Article

\title{
Thermomechanical and Morphological Properties of Poly(ethylene terephthalate)/Anhydrous Calcium Terephthalate Nanocomposites
}

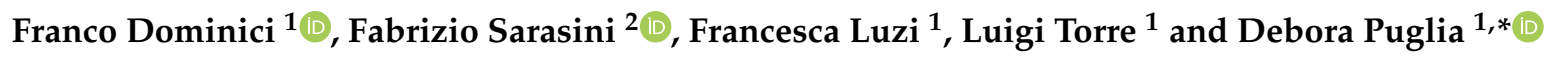 \\ 1 Civil and Environmental Engineering Department, University of Perugia, Strada di Pentima 4, \\ 05100 Terni, Italy; franco.dominici@unipg.it (F.D.); francesca.luzi@unipg.it (F.L.); luigi.torre@unipg.it (L.T.) \\ 2 Department of Chemical Engineering Materials Environment, Sapienza-Università di Roma and UdR \\ INSTM, Via Eudossiana 18, 00184 Roma, Italy; fabrizio.sarasini@uniroma1.it \\ * Correspondence: debora.puglia@unipg.it; Tel.: +39-0744-492916
}

Received: 1 December 2019; Accepted: 21 January 2020; Published: 30 January 2020

\begin{abstract}
Calcium terephthalate anhydrous salts (CATAS), synthetized by reaction of terephthalic acid with metal (Ca) oxide were incorporated at different weight contents $(0-30 \mathrm{wt}$. \%) in recycled Poly(ethylene terephthalate) (rPET) by melt processing. Their structure, morphology, thermal and mechanical properties (tensile and flexural behavior) were investigated. Results of tensile strength of the different formulations showed that when the CATAS content increased from 0.1 to $0.4 \mathrm{wt}$. \%, tangible changes were observed (variation of tensile strength from 65.5 to $69.4 \mathrm{MPa}$, increasing value for E from 2887 up to $3131 \mathrm{MPa}$, respectively for neat rPET and rPET_0.4CATAS). A threshold weight amount (0.4 wt. \%) of CATAS was also found, by formation at low loading, of a rigid amorphous fraction at the rPET/CATAS interface, due to the aromatic interactions ( $\pi-\pi$ conjugation) between the matrix and the filler. Above the threshold, a restriction of rPET/CATAS molecular chains mobility was detected, due to the formation of hybrid mechanical percolation networks. Additionally, enhanced thermal stability of CATAS filled rPET was registered at high content ( $T_{\max }$ shift from 426 to $441^{\circ} \mathrm{C}$, respectively, for rPET and rPET_30CATAS), essentially due to chemical compatibility between terephthalate salts and polymer molecules, rich in stable aromatic rings. The singularity of a cold crystallization event, identified at the same loading level, confirmed the presence of an equilibrium state between nucleation and blocking effect of amorphous phase, basically related to the characteristic common terephthalate structure of synthetized Ca-Metal Organic Framework and the rPET matrix.
\end{abstract}

Keywords: recycled poly(ethylene terephthalate); rPET; Calcium terephthalate salts; high performance nanocomposites

\section{Introduction}

Disposal of waste materials has become an urgent problem that can be solved by following two general paths: re-using the materials disposed, for suitable applications, as received, or recycling the waste to produce regenerated materials that could be applied again in the same or in another industrial field [1]. For instance, waste poly(ethylene terephthalate) (PET) plastic waste is neither biodegradable nor compostable, and due to its wide use worldwide substantial disposal problems are created. Recycling has emerged as the most practical method to deal with this issue, especially with products such as recycled PET (rPET) beverage bottles or fibers for textiles [2].

On the other hand, although PET is a recyclable polyester, its post-consumer reuse is limited by the weakening of its physical-mechanical properties, due to the reduction of molecular weight and viscosity, derived from the cleavage of the chains during processing [3]. As a solution to this 
problem, extruded blends with satisfactory properties based on virgin PET, with marginal proportions of rPET, were developed and used at an industrial level. However, it is necessary to increase the use of recycled PET in these mixed formulations to reduce costs and contribute to compliance with increasingly stringent regulations on plastic waste disposal.

To achieve the result of using increasing fractions of rPET without adding virgin material, it is mandatory to increase the mechanical properties of the polymer with the incorporation of low cost, commercially available nanoparticles/nanofillers [4]. There are many examples available in the literature dealing with the selection of unmodified or chemically modified layered nanoclays [5-7].

However, even if it was shown that substantial increase of mechanical properties can be achieved by high MMT (montmorillonite) content and optimum strength and stiffness at low level [8], the main limit of the use of organo-modified nanoclays relies in the decomposition of alkylammonium ether that can influence the PET degradation during the processing. A recent paper investigated the use of graphene nanoplatelets [9], demonstrating how the higher-order structure of PET can be tuned by considering different graphene loading. The authors interestingly found that the presence of a significant rigid amorphous fraction (RAF) in the nanocomposites increased with an increase in the graphene loading, while at low loadings the stiffening effect was observed to be quite small in the glassy state region. At a value of $2 \mathrm{wt}$. \%, graphene formed a mechanical percolation network with the RAF of PET and the PET chains were geometrically restricted by the incorporation of graphene, resulting in an unexpectedly higher modulus of nanocomposites both below and above $\mathrm{T}_{\mathrm{g}}$.

The effect of the nanometric calcium terephthalate anhydrous salts (CATAS) was studied in analogy to the above mentioned PET/GNP (polyethylene terephthalate/graphene nanoparticles) nanocomposites work. The idea is to design a circular use of PET, using terephthalic acid (TPA) recovered from the hydrolysis of PET for the preparation of terephthalate salts of various metals such as aluminum, magnesium, sodium, calcium potassium, etc. $[10,11]$. The production of these salts with nano-sized lamellar structure can be obtained with appropriate control of the reaction parameters [12,13]. Many different terephthalate salts, or metal-organic framework (MOFs) may be obtained by using sodium, potassium, aluminum, magnesium, calcium and other metals salts $[14,15]$. They are hybrid materials, composed of metal nodes and coordinating organic linkers, arranged in highly regular motifs that lead to materials exhibiting ultra-high surface areas. Applications are therefore proposed that use this porosity for reversible host-guest behavior, for example, in gas storage, catalysis and drug delivery. Attempts were made to develop existing MOFs and explore new applications using known functionalities, and introducing flexibility, defects and stimuli responsive behavior [16]. The formation of nanocomposites by combining MOFs with more processable materials such as polymers, not only engages with the theme of new materials discovery, but also offers new solutions for the manufacturing of robust bulk structures.

A few examples are available in the scientific literature on the use of these salts in thermoplastic nanocomposites, as in the case of applications that consider terephthalate salts in batteries [17-19] or gas separation applications, by taking into advantage of their defined porosity, high surface area, and catalytic activity. A recent review covers various topics of $\mathrm{MOF} /$ polymer research, where $\mathrm{MOF} /$ polymer hybrid and composite materials are highlighted, encompassing a range of material classes, such as bulk materials, membranes, and dispersed materials [20].

On the other hand, the chemical compatibility between the terephthalate salts and the polymer molecules, rich in stable aromatic rings, suggested the possibility of investigating the role of these salts in the thermomechanical behavior of recycled PET.

The objective of the present investigation was to study the structure of rPET_CATAS nanocomposites and the effect of nanofillers introduction on mechanical properties. The study was conducted by selecting two levels of loadings (0.1-1 wt. \% and 2-30 wt. \%), aiming to correlate the internal structure with the bulk thermomechanical performance of recycled PET. We specifically aimed to study these properties from the different perspective of evaluating not only the dispersibility 
at the macrolevel, but also checking the higher-order structure of the polymeric matrix in presence of the selected nanofillers.

\section{Materials and Methods}

Polyethylene terephthalate (I. V., $0.65 \mathrm{dl} / \mathrm{g}$, moisture content $1.3 \%$, bulk density $250-350 \mathrm{~kg} \mathrm{~m}^{-3}$ ) was supplied by Extremadura Torrepet (Torremejia, Spain). The recycling process adopted by the company intended to recycle post-consumer food grade poly(ethylene terephthalate) containers to produce recycled PET pellets. A four steps process consisted of in house treatment of PET bottles into hot caustic, drying and extrusion of flakes into pellets under vacuum, continuous feeding to a reactor for crystallization at high temperature, under atmospheric pressure for a predefined residence time, after that decontamination by solid state polymerisation process (SSP) is considered. A nanometric metal organic framework consisting of Calcium ions as metal clusters coordinated to terephthalic acid as organic ligand was synthesized in our laboratories to be used as filler in the nanocomposites. Calcium oxide, terephthalic acid, ammonia and water chemical reagents were supplied by Sigma Aldrich (Milan, Italy). The synthesis method is briefly described in the next section.

\subsection{Preparation of Terephthalate Salts}

Powdered terephthalic acid (TPA) was solubilized in an alkaline solution of water and ammonia with stirring at $80^{\circ} \mathrm{C}$ for $1 \mathrm{~h}$. Then, calcium oxide was added in a stoichiometric proportion to the acid according to Reaction (1):

$$
\mathrm{C}_{8} \mathrm{H}_{6} \mathrm{O}_{4}+\mathrm{CaO}+2 \mathrm{H}_{2} \mathrm{O} \rightarrow \mathrm{C}_{8} \mathrm{H}_{4} \mathrm{O}_{4} \mathrm{Ca} \bullet 3 \mathrm{H}_{2} \mathrm{O}
$$

The solution was kept under stirring at $80^{\circ} \mathrm{C}$ for $30 \mathrm{~min}$, after that insoluble calcium terephthalate precipitated forming a whitish deposit on the bottom. The solution was filtered, and the solid residue subjected to appropriate washings to eliminate unwanted reaction residues. At the end of the synthesis, calcium terephthalate trihydrate is obtained. To eliminate both moisture and water-bound molecules, the product was kept in a vacuum oven for $2 \mathrm{~h}$ at $190{ }^{\circ} \mathrm{C}$. Finally, anhydrous calcium terephthalate (CATAS) was pulverized and sieved to eliminate any conglomerates of salts.

\subsection{Production of Composite Materials}

Composite materials were manufactured using the melt mixing method by blending the recycled polyethylene terephthalate matrix with the calcium terephthalate salts as shown in Table 1. A co-rotating twin-screw extruder, Microcompounder $5 \& 15$ cc by DSM (DSM explorer $5 \& 15$ CC Micro Compounder, Xplore Instruments BV, Sittard, The Netherlands) was used for the mixing at $90 \mathrm{rpm}$ for $60 \mathrm{~s}$ by setting a temperature profile of $250-255-265^{\circ} \mathrm{C}$ in the three heating zones from top to die. A Micro Injection Molding Machine 10cc, Xplore line by DSM (DSM explorer 5\&15 CC Micro Compounder, Xplore Instruments BV, Sittard, The Netherlands) was used to produce the samples according to the standards for flexural and tensile tests. An adequate pressure/time profile was used for the injection of each type of samples, while barrel and mold temperatures were set at 280 and $120^{\circ} \mathrm{C}$, respectively.

Table 1. Developed formulations based on rPET and CATAS.

\begin{tabular}{ccc}
\hline Sample Name & rPET [\%] wt. & CATAS [\%] wt. \\
\hline rPET & 100 & - \\
rPET_0.1CATAS & 99.9 & 0.1 \\
rPET_0.25CATAS & 99.75 & 0.25 \\
rPET_0.4CATAS & 99.6 & 0.4 \\
rPET_0.5CATAS & 99.5 & 0.5 \\
rPET_1CATAS & 99 & 1 \\
rPET_2CATAS & 98 & 2 \\
rPET_3CATAS & 97 & 3 \\
rPET_10CATAS & 90 & 10 \\
rPET_20CATAS & 80 & 20 \\
rPET_30CATAS & 70 & 30 \\
\hline
\end{tabular}




\subsection{Characterization of Terephthalate Salts and rPET/CATAS Nanocomposites}

Morphological characterization of salts and rPET/CATAS nanocomposites was carried out using a field emission scanning electron microscope (FESEM) Supra 25 by Zeiss (Oberkochen, Germany) taking micrographs with an accelerating voltage of $5 \mathrm{kV}$ at different magnifications. Previously, the samples were gold sputtered to provide electric conductivity.

X-ray diffraction (XRD) analysis was performed with a diffractometer X'Pert PRO by Philips (Malvern Panalytical Ltd., Malvern, UK) $(\mathrm{CuK} \alpha$ radiation $=1.54060 \AA)$ at room temperature. XRD patterns were collected in the range of $2 \theta=10-80^{\circ}$ with a step size of $0.02^{\circ}$ scan and a time per step of $34 \mathrm{~s}$.

Thermal characteristics of rPET/CATAS nanocomposites were investigated with a temperaturemodulated differential scanning calorimeter (MDSC) Q200 by TA Instruments (TA Instrument, Q200, New Castle, DE, USA). A heating scan between 0 and $300^{\circ} \mathrm{C}$ was performed at a rate of $10^{\circ} \mathrm{C} / \mathrm{min}$ in nitrogen flow at $60 \mathrm{~mL} / \mathrm{min}$. A three phases model was adopted to describe the higher-order structure of $\mathrm{rPET} / \mathrm{CATAS}$ nanocomposites. It was demonstrated that sometimes $\Delta \mathrm{C}_{\mathrm{p}}$ at $\mathrm{T}_{\mathrm{g}}$ in semicrystalline polymers results inconsistent with the amorphous fraction $\left(X_{a}\right)$, if calculated as complement to one of the crystalline fraction $\left(X_{c}\right)$. In this case, it is possible to calculate the amorphous fraction with the variation of thermal capacity at $T_{g}$ and a total rigid fraction $\left(X_{f}=1-X_{a}\right)$ that consists of the crystalline phase and another fraction of a phase which remains rigid beyond the glass transition region. Since this rigid phase cannot be detected by $\Delta \mathrm{C}_{\mathrm{p}}$ at $\mathrm{T}_{\mathrm{g}}$ that is not properly amorphous phase and it does not have a crystalline structure, it was defined rigid amorphous phase $\mathrm{X}_{\text {raf }}$ :

$$
\begin{gathered}
\mathrm{X}_{\mathrm{a}}=\frac{\Delta \mathrm{C}_{\mathrm{P}-\text { meas }}^{\Delta \mathrm{Tg}}-\mathrm{W}_{\mathrm{CATAS}} * \Delta \mathrm{C}_{\mathrm{P}-\mathrm{CATAS}}^{\Delta \mathrm{Tg}}}{\Delta \mathrm{C}_{\mathrm{P}-\mathrm{aPET}}^{\Delta \mathrm{Tg}}}=\frac{\Delta \mathrm{C}_{\mathrm{P}-\mathrm{PET}}^{\Delta \mathrm{Tg}}}{\Delta \mathrm{C}_{\mathrm{P}-\mathrm{aPET}}^{\Delta \mathrm{Tg}}}=1-\mathrm{X}_{\mathrm{f}} \\
\mathrm{X}_{\mathrm{a}}=1-\left(\mathrm{X}_{\mathrm{c}}+\mathrm{X}_{\mathrm{raf}}\right)
\end{gathered}
$$

where $\Delta \mathrm{C}_{\mathrm{P}-\text { meas }}^{\Delta \mathrm{Tg}} \Delta \mathrm{C}_{\mathrm{P}-\mathrm{CATAS}}^{\Delta \mathrm{Tg}}, \Delta \mathrm{C}_{\mathrm{P}-\mathrm{aPET}}^{\Delta \mathrm{Tg}}$ are $\Delta \mathrm{C}_{\mathrm{p}}$ at $\mathrm{T}_{\mathrm{g}}$, respectively, for measured nanocomposites, CATAS and $100 \%$ amorphous neat PET, while $\mathrm{w}_{\text {CATAS }}$ is the weight fraction of the salts in the nanocomposites. It is assumed that $\Delta \mathrm{C}_{\mathrm{P}-\mathrm{aPET}}^{\Delta \mathrm{Tg}}=0.405 \mathrm{~J} \mathrm{~g}^{-1} \mathrm{~K}^{-1}$ and heat of melting of $100 \%$ crystalline PET is $\Delta \mathrm{H}_{\mathrm{m}-\mathrm{cPET}}^{0}=140 \mathrm{~J} \mathrm{~g}^{-1}$. [21].

Thermogravimetric analysis (TGA) on nanocomposites samples was carried out using Seiko Exstar 6300 from Seiko instruments (Seiko, Tokyo, Japan). Thermograms obtained from TGA analysis provides the information related to the thermal stability of material. About $10-15 \mathrm{mg}$ of the sample was subjected for TGA analysis, performed on the samples between room temperature and $900{ }^{\circ} \mathrm{C}$ with heating rate of $10^{\circ} \mathrm{C} / \mathrm{min}$ in nitrogen atmosphere.

A universal electronic dynamometer LR30K by LLOYD Instruments (Lloyd Instrument, Segens worth West, Foreham, UK) was used to carry out tensile tests by setting a cross-head speed of $5 \mathrm{~mm} \mathrm{~min}{ }^{-1}$, in accordance with ASTM D638 standard. Three points bending tests were carried out by setting a span between supports of $64 \mathrm{~mm}$ and loading at a deflection rate of $2 \mathrm{~mm} \mathrm{~min}^{-1}$, according to the standard ASTM D790. The analysis of mechanical tests data was carried out by using the Nexigen software (Elis (Electronic Instruments \& Systems) s.r.l., Rome, Italy).

Dynamic mechanical analysis of the rPET-based nanocomposites was performed with an Ares N2 rheometer (Rheometric Scientific, Reichelsheim, Germany), by testing samples of about $4 \times 10 \times 40 \mathrm{~mm}$, gripped with a gap of about $20 \mathrm{~mm}$ and tested with rectangular torsion at a frequency of $2 \pi \mathrm{rad} / \mathrm{s}$ with a strain of $0.05 \%$, with a temperature ramp of $3{ }^{\circ} \mathrm{C} / \mathrm{min}$ applied in the range from 30 to $180^{\circ} \mathrm{C}$. Storage $\left(G^{\prime}\right)$ and loss moduli $\left(G^{\prime \prime}\right)$ as a function of the temperature were determined. 


\section{Results and Discussion}

\subsection{Characterization of Calcium Terephthalate Salts}

The structural characteristics of terephthalate calcium salts are shown in Figure 1a [22-24]. The reaction between terephthalic acid and calcium oxide in water was carried out to produce calcium terephthalate trihydrate salts (CATS) [25]. The production process required an appropriate monitoring of reaction conditions, by acting on the kinetics and using appropriate additives to obtain the nanometric structures. Some attempts were made to optimize the characteristics of the fillers. Lastly, insoluble calcium terephthalate trihydrate salts were obtained by their precipitation in water. A heat treatment at $200{ }^{\circ} \mathrm{C}$ for $1 \mathrm{~h}$ in a vacuum oven transforms the trihydrate salts (Figure $1 \mathrm{~b}$ ) into the corresponding anhydrous calcium terephthalate (CATAS) salts (Figure 1c): this step was necessary, being the presence of bound water harmful for the melt blending process of the nanocomposites, due to hydrolysis phenomena and formation of cavities within the samples.
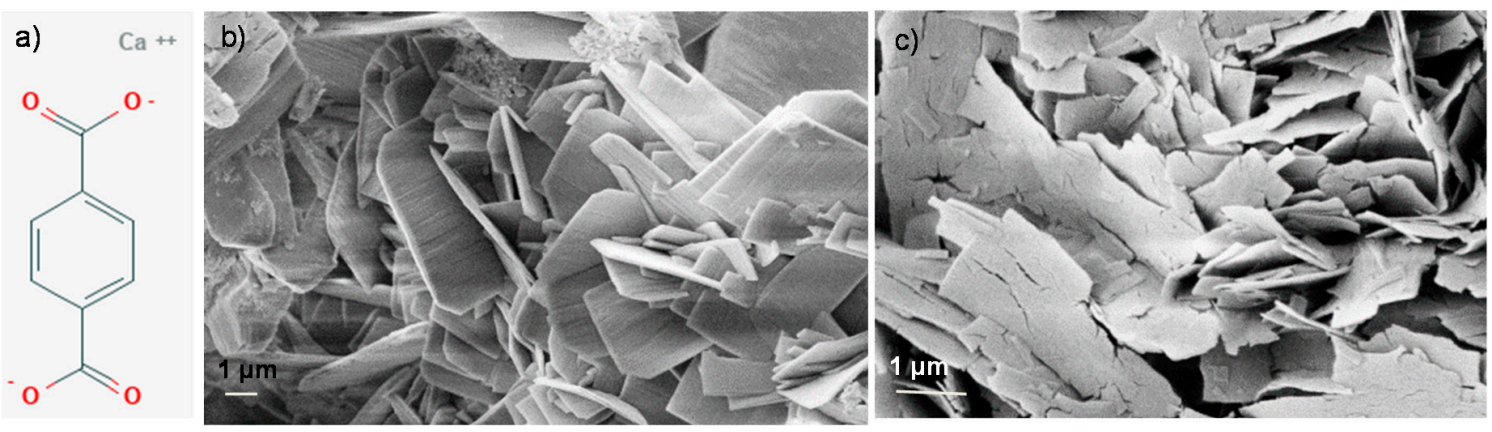

Figure 1. Chemical structure of calcium terephthalate salts (a) and FESEM morphology in their hydrated (b) and anhydrous state (c).

Figure $1 \mathrm{c}$ shows that after the dehydration $\left(\mathrm{T}=200^{\circ} \mathrm{C}\right)$, the anhydrous salts have cracks with rough surface, revealing that volume contraction happens in the dehydration process [26].

The X-ray diffraction pattern of CATAS shows diffraction peaks at $18.8^{\circ}, 21.6^{\circ}, 25.7^{\circ}, 26.9^{\circ}$, and $31.2^{\circ}$. According to the report by Mou et al., this structure can be indexed with a space group of C2/c (n. 15) as monoclinic crystal system [17] (Figure 2a). More precisely, the process involves rotation of the ligand, disconnection, and protonation of the carboxylate group on one side and partial disconnection and reformation of $\mathrm{Ca}-\mathrm{O}$ bond on the other side of the ligand. Mazaj proposes a reversible hydration/dehydration mechanism, which through the breaking of the bonds between $\mathrm{Ca}^{2+}$ and carboxylate groups, rotating of ligand and re-coordination of $\mathrm{COO}^{-}$groups to $\mathrm{Ca}^{2+}$ centers . The crystal-to-crystal transformations are driven by the tendencies to change the bonding modes between $\mathrm{COO}^{-}$and $\mathrm{Ca}^{2+}$ with the change of $\mathrm{Ca}^{2+}$ coordination number. Thus, the decrease of $\mathrm{Ca}^{2+}$ coordination number, which is usually a consequence of activation, leads to a structural rearrangement, with expansion or contraction of the pores [27].

TG and DTG plots for CATS and anhydrous CATAS (Figure $2 \mathrm{~b}, \mathrm{c}$ ) showed multiple decomposition steps. In the case of CATS, the first peak at a temperature lower than $100{ }^{\circ} \mathrm{C}$ refers to the loss of hygroscopic water and any residual volatile additives present during the reaction. The second peak, at a temperature between $100{ }^{\circ} \mathrm{C}$ and $170{ }^{\circ} \mathrm{C}$, refers to the loss of molecular water since a weight loss of $22 \%$ (moisture free weight) corresponds to three water molecules per formula unit. The decomposition of the acid salts involved the breaking of the carboxyl groups, the formation of carbonates, and the release of gaseous products. The subsequent mass losses are due to thermal destruction of organic ligands over $500{ }^{\circ} \mathrm{C}$. Figure $2 \mathrm{c}$ shows that in the case of anhydrous salts, the main weight loss can be detected between 500 and $800{ }^{\circ} \mathrm{C}$ that corresponds to the decomposition of the organic ligands [25,28]. Evaluation of thickness distribution showed that the average size for anhydrous salts was set at $50 \pm 5 \mathrm{~nm}$. 

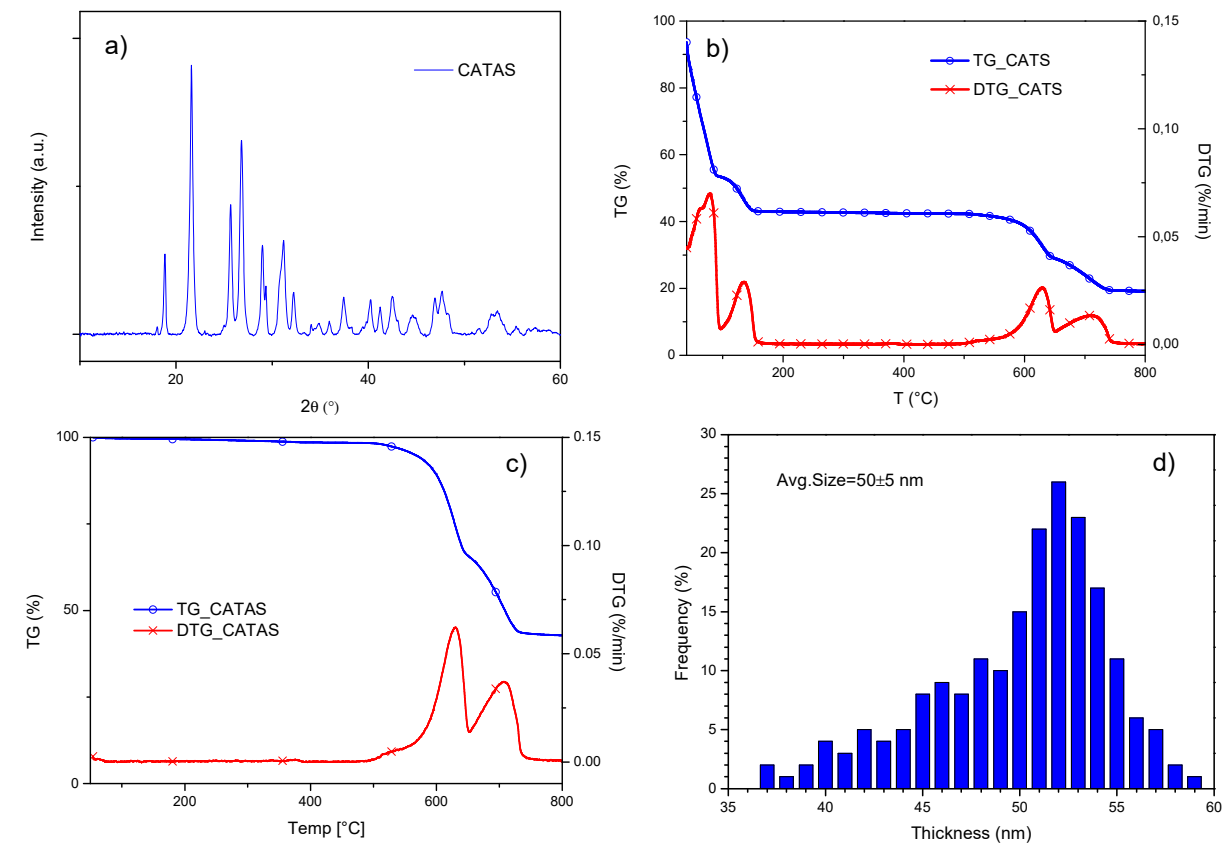

Figure 2. XRD profile for CATAS (a); TG/DTG curves for CATS (b); and CATAS nanofillers (c); thickness distribution for CATAS (d).

\subsection{Characteristics of $r$ PET/CATAS Nanocomposites}

\subsubsection{DMTA (Dynamic Mechanical Thermal Analysis)}

To evaluate the influence of CATAS on viscoelastic behavior of rPET matrix, dynamic mechanical thermal analysis of high loaded rPET nanocomposites was performed. The variation of the storage moduli $\left(G^{\prime}\right)$ and $\tan \delta\left(G^{\prime \prime} / G^{\prime}\right)$ with temperature are presented in Figure 3a,b, respectively. The storage modulus behavior in Figure 3a shows that the rPET/CATAS nanocomposites possessed higher storage modulus compared to the reference $r P E T$ below and above the $T_{g}$. A gradual increase in storage modulus is observed with increase in CATAS content in rPET matrix (Table 2). Among the nanocomposite samples, rPET_30CATAS had the highest storage modulus compared to reference rPET and other nanocomposite samples. The adsorption of the CATAS onto the macromolecular chains of rPET leads to a constraint in the chains movement and therefore, an improved storage modulus [29], while a sharp decrease in the moduli was observed at the glass-rubber transition at around $90{ }^{\circ} \mathrm{C}$ [4]. Regarding the glass temperatures $\left(\mathrm{T}_{\mathrm{g}}\right)$, results of $\tan \delta$ from the DMTA tests can be seen in Figure $3 \mathrm{~b}$ and Table 2 . Compared to rPET, the nanocomposites had the maximum of the peak at slightly higher temperature with increasing content of CATAS temperatures. Thus, the increased value of $T_{g}$ resulting on the addition of nanometric salts confirms that the mobility of polymeric chains was slightly reduced, which in turn affected the flexibility of the samples. On the other hand, the peak values of $\tan \delta$ increased with an increase in CATAS up to $10 \%$ wt., where the influence of the elastic component starts to prevail on the viscous one: at higher filler contents (20-30 wt. \%), a decrease in the tan $\delta$ is observed, mainly due to a combination of viscoelastic and physical behavior. In details, a prevalent rigid amorphous fraction $\left(X_{\text {raf }}\right)$, formed in the interfacial region between rPET and CATAS, justifies the increase in elastic modulus, so that the nanofiller is able to restrict the molecular movement of the amorphous rPET chains both in the interfacial region and in the amorphous region. This restriction is also evident in the registered $G^{\prime}$ values when measured at $150{ }^{\circ} \mathrm{C}$ (after Tg) (Table 2): the limited decrease in $\mathrm{G}^{\prime}$ after the Tg can be mainly related to the CATAS physical interactions that when present in large amount physically constrains the mobility of the polymeric chains. 

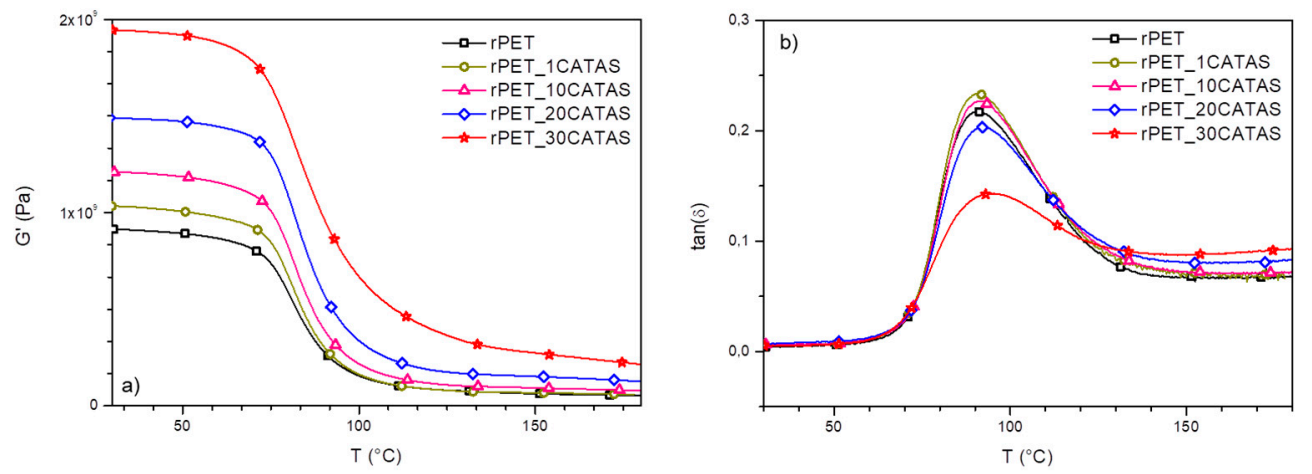

Figure 3. G' (a) and tan $\delta$ curve (b) from DMTA tests for rPET and rPET/CATAS nanocomposites.

Table 2. Calculated values of $\tan \delta$ and $\mathrm{G}^{\prime}$ at 50 and $150{ }^{\circ} \mathrm{C}$ for the rPET/CATAS nanocomposites.

\begin{tabular}{|c|c|c|c|}
\hline MATERIAL & $\begin{array}{c}\mathrm{G}^{\prime} @ \mathrm{~T}=50^{\circ} \mathrm{C} \\
\left(\times 10^{9} \mathrm{~Pa}\right)\end{array}$ & $\begin{array}{c}\mathrm{G}^{\prime} @ \mathrm{O}=150^{\circ} \mathrm{C} \\
\left(\times 10^{8} \mathrm{~Pa}\right)\end{array}$ & $\begin{array}{c}\mathrm{T}_{\mathrm{g}}(\text { at } \tan \delta \text { peak }) \\
\left({ }^{\circ} \mathrm{C}\right)\end{array}$ \\
\hline rPET & 0.89 & 0.61 & 90.41 \\
\hline rPET_1CATAS & 1.00 & 0.68 & 90.48 \\
\hline rPET_10CATAS & 1.19 & 0.96 & 90.89 \\
\hline rPET_20CATAS & 1.47 & 1.54 & 91.29 \\
\hline rPET_30CATAS & 1.92 & 2.76 & 93.43 \\
\hline
\end{tabular}

\subsubsection{Mechanical Characterization (Flexural and Tensile Tests)}

The influence of CATAS presence on tensile and flexural properties of rPET nanocomposites was also investigated. Stress-strain curves for flexural and tensile tests of representative samples are respectively reported in Figure 4a,b, while the variations of the tensile and flexural parameters of all the rPET_CATAS nanocomposites are included in Figure 4c,d. Complementary information on performed tests are also summarized in Table 3 . The results of tensile strength of the different formulations showed that when the CATAS content increased from 0.1 to $0.4 \mathrm{wt}$. \%, tangible changes were observed (from 65.5 to $69.4 \mathrm{MPa}$ ) and this improvement can be attributed to strong interaction between the salts and the polymer matrix owing to uniform dispersion of nanoparticles, as further confirmed by following FESEM analysis. Besides, amounts of nanoparticles higher than $0.4 \mathrm{wt}$. $\%$ negatively affects the mechanical properties of the nanocomposites, due to agglomeration of nanoparticles [30]. The possible formation of mechanical percolation networks with the RAF of rPET at interfacial regions with confined rPET matrix could justify these results above $0.4 \mathrm{wt}$. \% of CATAS loading. As already observed by Aoyama et al. for grapheme nanoparticles [9], a mechanical percolation threshold can be estimated at these low loading level (between 1 and $2 \mathrm{wt}$. \% in the case of GNP): a rigid amorphous fraction of rPET in nanocomposites is formed at the rPET/CATAS interface, due to the aromatic interactions between the matrix and the filler, both of which contain a $\pi-\pi$ conjugation. Molecular chains of rPET in nanocomposites are clearly confined, in compared with neat rPET: below $0.4 \% \mathrm{wt}$. of CATAS loading, the restriction of rPET chains is mostly limited to the interfacial region (i.e., $\mathrm{X}_{\mathrm{raf}}$ ), therefore, the stiffness enhancement effect is dictated by simple mixing rule (increasing value for $\mathrm{E}$ from 2887 up to $3131 \mathrm{MPa}$, respectively for neat rPET and rPET_0.4CATAS). Above $0.4 \mathrm{wt}$. \%, the restriction of molecular chains of rPET/CATAS is in turn due to the formation of hybrid mechanical percolation networks of CATAS with the $X_{\text {raf }}$ of rPET that geometrically restricts the mobility of rPET chains in rPET. This effect was visible also in the registered values for strain at break, where a visible decrease was noted up to the same level of CATAS amount ( $0.4 \mathrm{wt}$. \%), after that the values showed an increase, due to the absence of $X_{\text {raf }}$ fraction between 0.4 and 2 wt. \% of CATAS. When the loading was clearly too high (2-30 wt. \%), the rPET nanocomposites became extremely fragile.

Similar trend in terms of mechanical performance was found for the nanocomposites in flexural tests. Below the mechanical percolation threshold, estimated between $1 \%$ and $2 \%$ for 
these nanostructured systems, the flexural strength remains constant. In particular, a threshold value of $0.4 \%$ CATAS for the formation of a mechanical percolation network is conceivable; this model justifies the improvements in the mechanical characteristics of the rPET_0.4CATAS system. The deformation reaches values two times higher than the matrix, maintaining a good flexural strength. However, flexural strength decreases for composites with higher nanofiller loadings (beyond 0.4 wt. \%), which could be due to agglomeration of CATAS and reduced interfacial interaction between rPET and nanofiller [31].
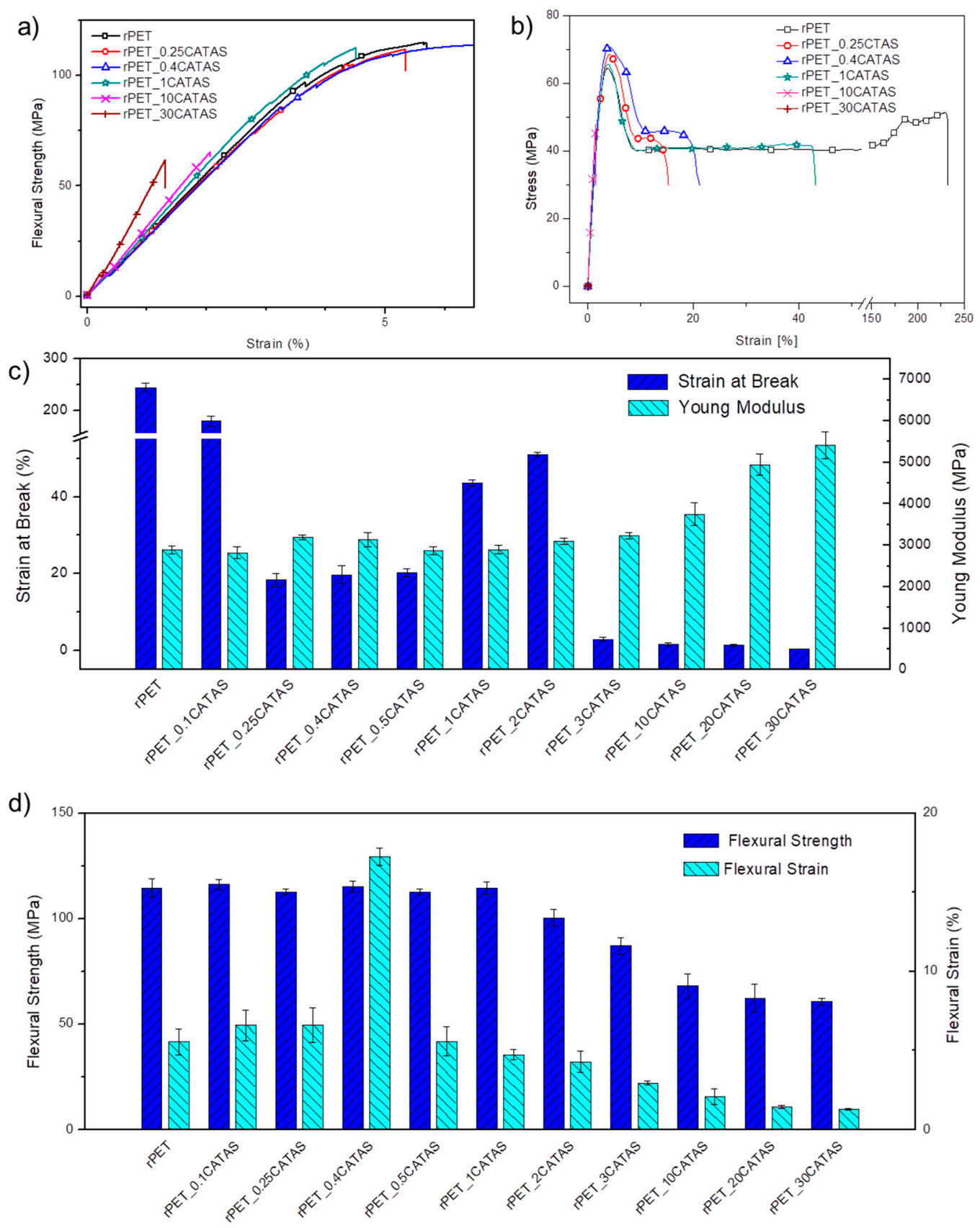

Figure 4. Stress-strain curves from flexural (a) and tensile tests (b), variation of tensile modulus and strain at break (c), variation of flexural stress and strain (d) for rPET_CATAS nanocomposites at the different loading levels.

This result can be justified again by the formation of aromatic interactions between the matrix and the filler. At this threshold the effect of CATAS is optimal and an exceptional performance is 
obtained. At values of reinforcement higher than the $2 \mathrm{wt}$. \% CATAS threshold, the excess filler produces block of molecular flows (due to the mechanical effect at the filler/matrix interface and due to the increasing presence of the rigid amorphous phase, which blocks the structure of the composite limiting the deformability of the samples). In high-filling samples an increase in flexural modulus (see Figure 4a) is obtained but, when the deformability limit becomes excessive, the fragile behavior causes premature failure of the samples.

Table 3. Tensile parameters of rPET_CATAS nanocomposites at the different loading levels.

\begin{tabular}{|c|c|c|c|c|c|c|c|c|c|c|}
\hline \multirow{2}{*}{$\begin{array}{c}\text { MATERIAL } \\
\text { rPET }\end{array}$} & \multicolumn{2}{|c|}{$\begin{array}{c}\text { Young's Modulus } \\
\text { (MPa) }\end{array}$} & \multicolumn{2}{|c|}{$\begin{array}{l}\text { Stress } \\
(\mathrm{MPa})\end{array}$} & \multicolumn{2}{|c|}{$\begin{array}{c}\text { Strain at Maximum } \\
\text { Stress }(\%)\end{array}$} & \multicolumn{2}{|c|}{$\begin{array}{l}\text { Stress at Break } \\
(\mathrm{MPa})\end{array}$} & \multicolumn{2}{|c|}{$\begin{array}{c}\text { Strain at Break } \\
(\%)\end{array}$} \\
\hline & 2887 & \pm 178 & 65.5 & \pm 3.6 & 3.99 & \pm 0.21 & 41.0 & \pm 5.2 & 244.2 & \pm 16.9 \\
\hline rPET_0.1CATAS & 2819 & \pm 283 & 61.7 & \pm 4.2 & 3.68 & \pm 0.23 & 41.7 & \pm 3.1 & 178.9 & \pm 20.7 \\
\hline rPET_0.25CATAS & 3186 & \pm 115 & 68.9 & \pm 2.3 & 3.98 & \pm 0.28 & 41.9 & \pm 1.9 & 18.3 & \pm 3.6 \\
\hline rPET_0.4CATAS & 3131 & \pm 342 & 69.4 & \pm 1.7 & 3.89 & \pm 0.27 & 42.4 & \pm 3.2 & 19.7 & \pm 4.5 \\
\hline rPET_0.5CATAS & 2867 & \pm 201 & 66.8 & \pm 0.1 & 3.90 & \pm 0.28 & 39.6 & \pm 0.5 & 20.2 & \pm 2.3 \\
\hline rPET_1CATAS & 2898 & \pm 206 & 67.4 & \pm 2.5 & 3.78 & \pm 0.26 & 43.2 & \pm 1.7 & 43.6 & \pm 1.6 \\
\hline rPET_2CATAS & 3099 & \pm 145 & 64.8 & \pm 1.4 & 3.12 & \pm 0.38 & 39.4 & \pm 0.5 & 51.0 & \pm 0.9 \\
\hline rPET_3CATAS & 3225 & \pm 148 & 61.9 & \pm 8.8 & 2.91 & \pm 0.36 & 61.8 & \pm 8.8 & 2.9 & \pm 1.1 \\
\hline rPET_10CATAS & 3751 & \pm 549 & 45.5 & \pm 14.1 & 1.60 & \pm 0.42 & 45.5 & \pm 14.1 & 1.6 & \pm 0.7 \\
\hline rPET_20CATAS & 4943 & \pm 517 & 36.5 & \pm 10.2 & 1.34 & \pm 0.51 & 36.5 & \pm 10.3 & 1.3 & \pm 0.5 \\
\hline rPET_30CATAS & 5408 & \pm 645 & 0.3 & 0.0 & 0.04 & 0.01 & 0.3 & 0.0 & 0.3 & \pm 0.1 \\
\hline
\end{tabular}

\subsubsection{XRD Analysis}

The XRD patterns of recycled PET and some representative rPET/CATAS nanocomposites (Figure 5) indicate semi-crystalline triclinic structure for rPET matrix.
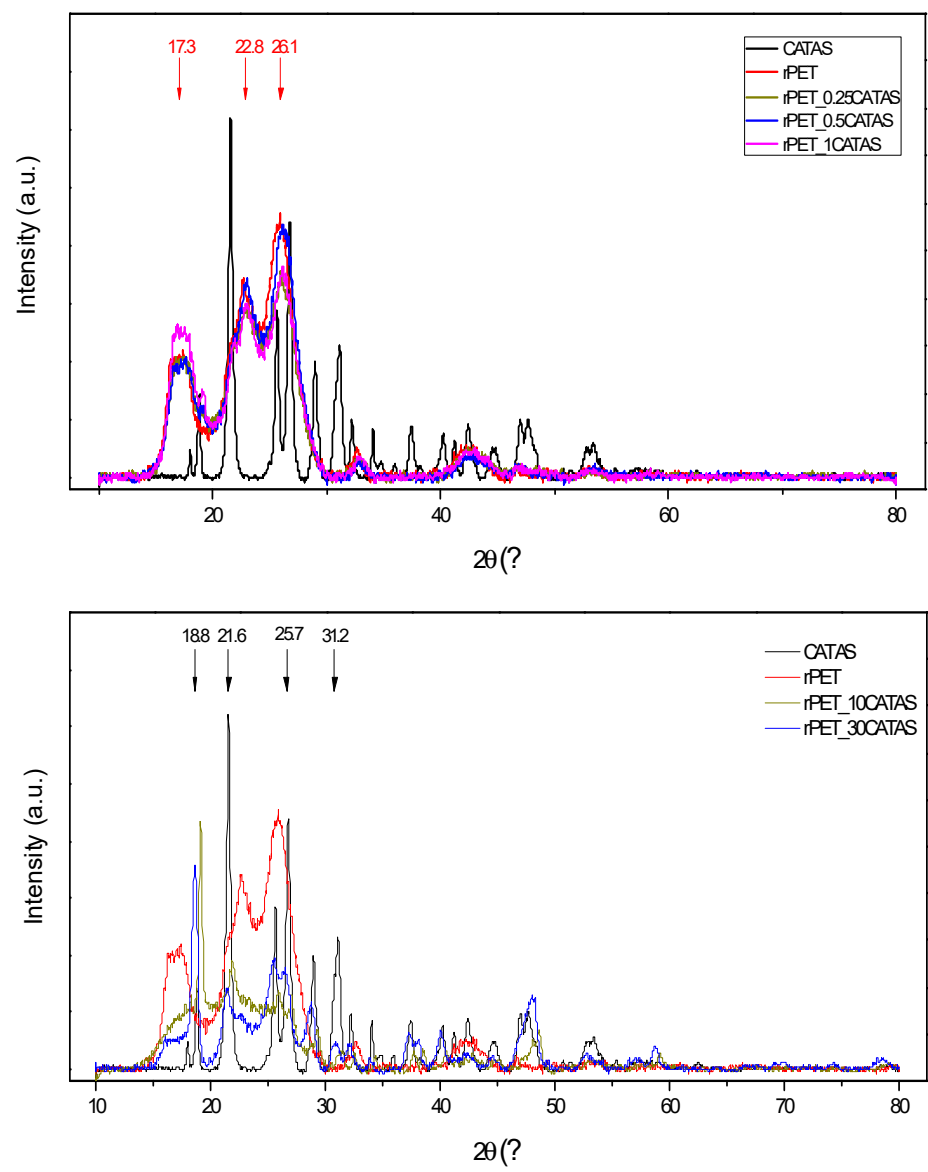

Figure 5. XRD diffraction curves for rPET and rPET/CATAS nanocomposites at low and high loadings. 
Semi-crystalline PET typically shows characteristic crystalline XRD peaks at $2 \theta=17.3,21.7,22.8$, 26.1 and $32.5^{\circ}$, corresponding to the (010), (111), (110), (100), (021), (002) and (101) crystal planes [32]. Although some minor peaks are observed as the amount of CATAS increased in the sample, the intensities of the peaks for rPET decreased in presence of increasing amount of salts, while in parallel the signals related to the CATAS increased, indicating that polymer and salts maintained their original structure [33].

\subsubsection{Morphological Analysis}

The morphology of the samples was investigated by using FESEM analysis, performed on the fractured surfaces of the specimens after the tensile test. The SEM images of unreinforced rPET and rPET_CATAS nanocomposite samples at different loading levels are presented in Figure 6. It can be seen a gradual transition from ductile fractured surface of rPET to essentially fragile morphology of rPET_10CATAS, while at intermediate fraction (1 wt. \% CATAS) the failure behavior changes, becoming partially brittle. This observation is consistent with the increasing content of amorphous fraction at higher concentrations: this fraction can act to prematurely fracture the composite, reducing the stiffness of the composite, due to CATAS role as stress concentration sites, facilitating crack initiation [34].
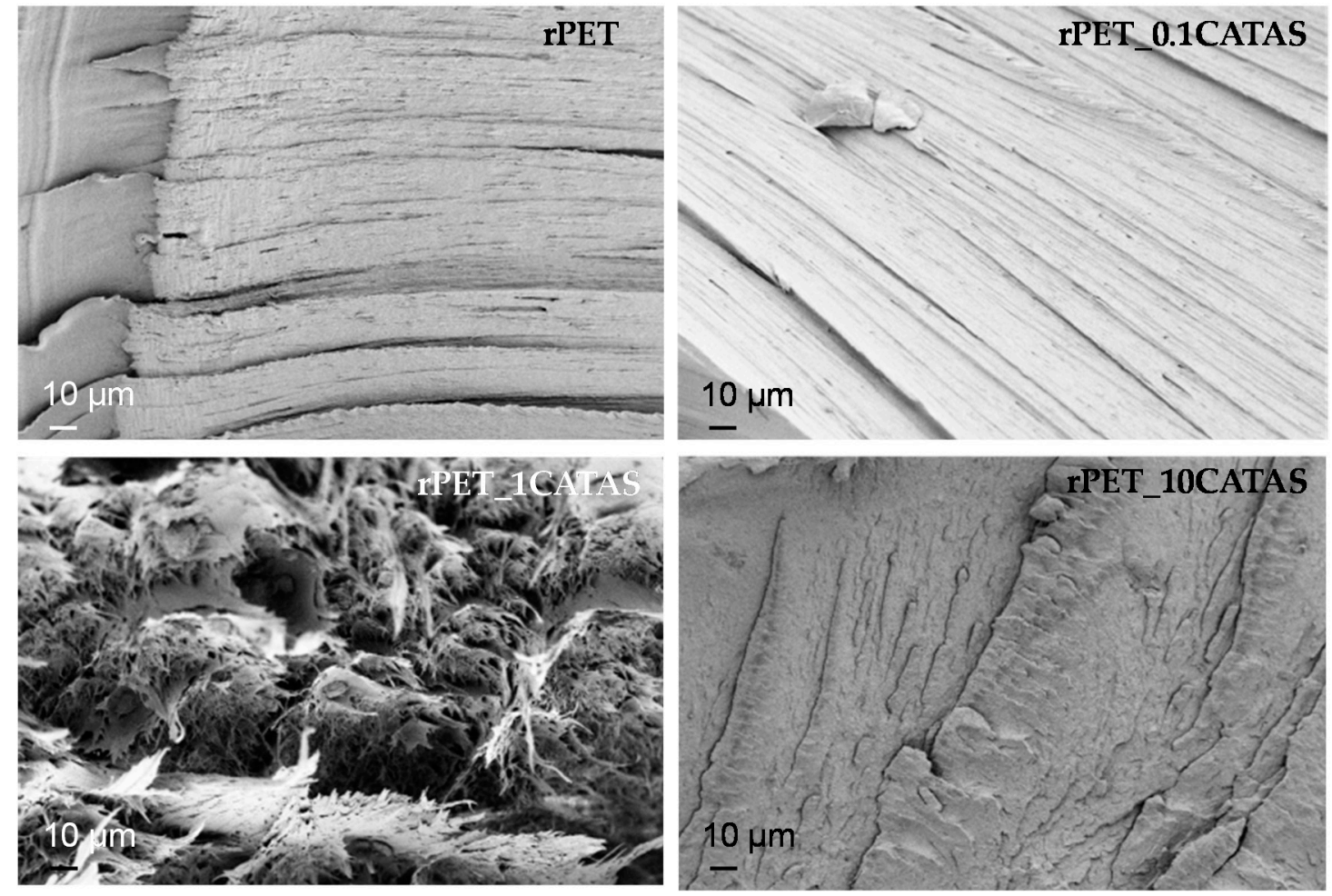

Figure 6. FESEM images of fractured surfaces for rPET and rPET/CATAS nanocomposites.

\subsubsection{Thermal Characterization}

TGA: The TG weight loss curves and first derivative TG curves for reference rPET and the nanocomposite samples under nitrogen atmosphere are presented in Table 4 and Figure $7 \mathrm{a}, \mathrm{b}$. Neat rPET exhibited a single-step decomposition profile: the main degradation process during TGA analysis under nitrogen atmosphere is due to the combined degradation processes-polymer chain degradation through end group initiated mechanism and the thermal degradation of the products formed during polymer chain degradation [35]. The thermal decomposition of polymer is leading to thermally stable cross-linked carbonaceous species which are not undergoing any further decomposition due to the presence of inert nitrogen atmosphere and hence the large amounts of residue at the end of TGA analysis. The addition of different amount of CATAS enhanced the thermal stability of the matrix to 
some extent (peak temperature shifted from $426{ }^{\circ} \mathrm{C}$ for neat rPET to 427 and $441{ }^{\circ} \mathrm{C}$ for rPET_3CATAS and rPET_30CATAS), respectively: nevertheless, all the formulations presented a degradation curve similar to the matrix, with a superposition, in the thermal degradation pattern, due to the concomitant decomposition of the salts [36]. The values of residual mass at the end of the tests, measured as $13.7 \%$, $12.3 \%$ and $23.6 \%$ for neat rPET, rPET_3CATAS and rPET_30CATAS, respectively, are in line with the expected values, according to the registered weight loss for CATAS ( $43 \%$ at the end of the test) already measured in Figure 2b. The decreased residual mass for the rPET_3CATAS system at the end of the test, in comparison with rPET, can be justified by considering that in addition to polymer decomposition, the presence of the alkaline earth metal-based MOF catalyzed the thermal degradation of the neat matrix, lowering the values for final mass residue.

Table 4. TGA parameters of rPET_CATAS nanocomposites at three representative loading levels $(0$, 3 and 30 wt. \%).

\begin{tabular}{ccccc}
\hline Material & $\begin{array}{c}\mathrm{T}_{\text {on }} \\
\left({ }^{\circ} \mathbf{C}\right)\end{array}$ & $\begin{array}{c}\mathbf{T}_{\mathbf{2 0}} \% \\
\left({ }^{\circ} \mathbf{C}\right)\end{array}$ & $\begin{array}{c}\mathbf{T}_{\max } \\
\left({ }^{\circ} \mathbf{C}\right)\end{array}$ & $\begin{array}{c}\text { Residual Mass (\%) } \\
\left(\text { at } \mathbf{9 0 0}{ }^{\circ} \mathbf{C}\right)\end{array}$ \\
\hline rPET & 350 & 417 & 426 & 13.7 \\
rPET_3CATAS & 350 & 418 & 427 & 12.3 \\
rPET_30CATAS & 335 & 439 & 441 & 23.6 \\
\hline
\end{tabular}
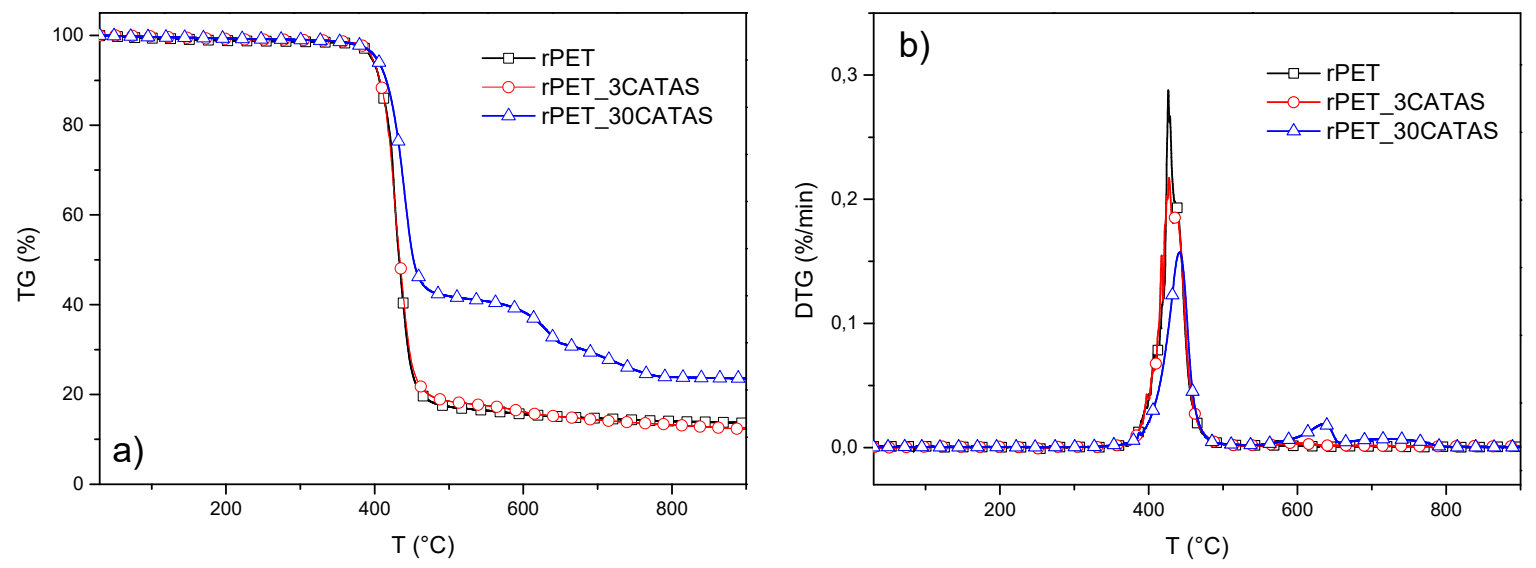

Figure 7. TG curve (a) and DTG curve (b) for rPET and rPET/CATAS nanocomposites at 3 and $30 \mathrm{wt}$. \% of CATAS.

DSC: DSC heating curves for neat rPET and rPET_CATAS nanocomposites, reported in Figure 8a (low loading) and Figure 8b (high loading), registered the presence of three main events during the heating scan: a stepwise endothermic changes for glass transition at around $76{ }^{\circ} \mathrm{C}$, an exothermic peak for cold crystallization at $117^{\circ} \mathrm{C}$, and one endothermic peak for crystal melting at $250{ }^{\circ} \mathrm{C}$ [9]. The peak heat flow for cold crystallization with very low quantity of CATAS nanocomposites become larger compared with that of neat rPET, indicating that CATAS play the role of nucleating agents for crystallization in rPET_0.1CATAS and rPET_0.25CATAS nanocomposite samples. Furthermore, the peak shapes of PET-based nanocomposites became wider, indicating that the nanocomposite cold crystallization process takes a longer time to complete than for neat rPET. This crystallization peak is negligible in rPET_0.4CATAS and becomes again visible in rPET_0.5CATAS as in rPET_0.25CATAS. Despite the variability observed across samples in terms of the cold crystallization behavior, it was observed for all of the samples that the crystallinity level is almost the same for all the nanocomposites with a slight increase at higher filler content. 

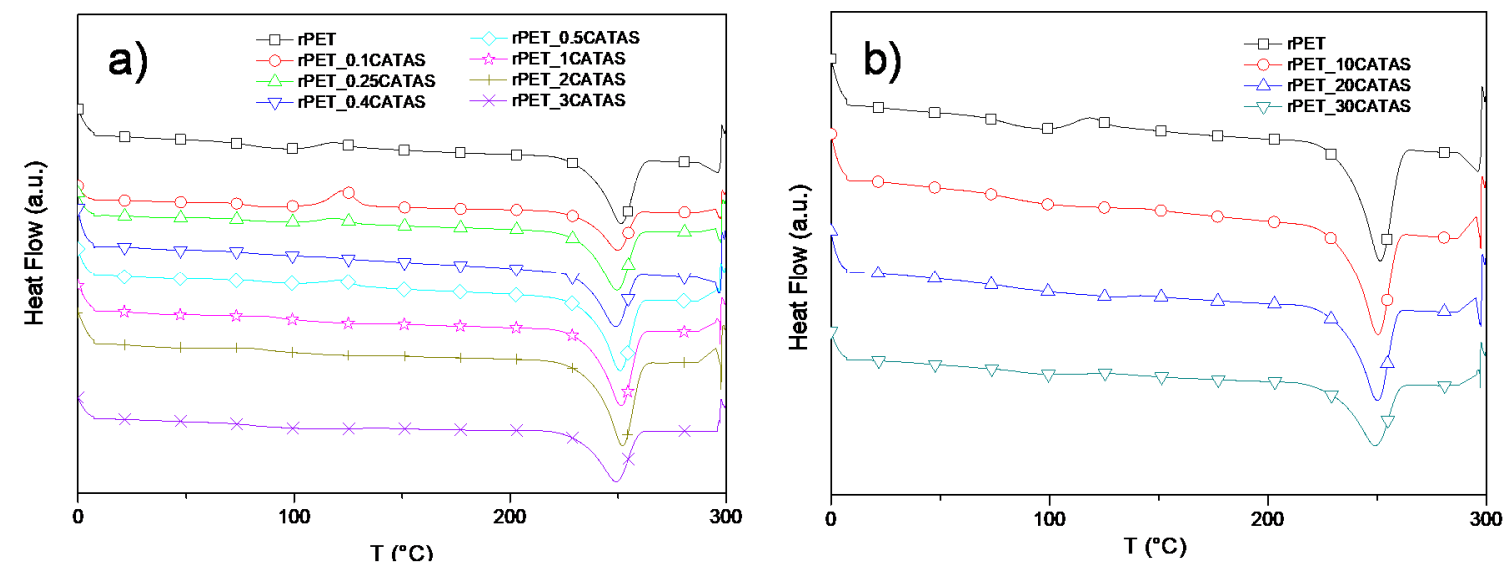

Figure 8. DSC heating scan for rPET and rPET/CATAS nanocomposites at low (a) and high (b) loading levels.

The presence of CATAS, in addition to the nucleating effect, produces a blocking effect of the amorphous phase causing the increase of the fraction of the rigid amorphous phase. At the lower percentages of filler, the nucleating effect is prevalent on the blocking so that the $X_{\text {raf }}$ remains lower than $12 \%$. It was hypothesized that the singularity of the rPET_0.4CATAS composite consists of a condition of equilibrium between the nucleating effect of the crystalline phase and the blocking effect of the amorphous phase, coordinating the terephthalate structure of the salts with the terephthalic chains of the matrix. This situation produces a slight increase of $X_{c}$ with a reduction of $X_{\text {raf }}$ to values close to rPET neat. The progressive increase of filler in the subsequent formulation bring to a prevalence of the blocking effect and then to a progressive increase of $X_{\text {raf }}$. The formation of an important fraction of a rigid amorphous phase limits the formation of crystals as opposed phenomena, hindering the peak of cold crystallization. In addition, during the heating, melting and reconstitution of crystallites reach to an equilibrium between the phases that is influenced by many factors as time, temperature, heating rate, etc. In our systems, a three-phase model show the phase ratio reported in Figure 9 that helps to give a comprehensive explanation of the mechanical results [37,38].

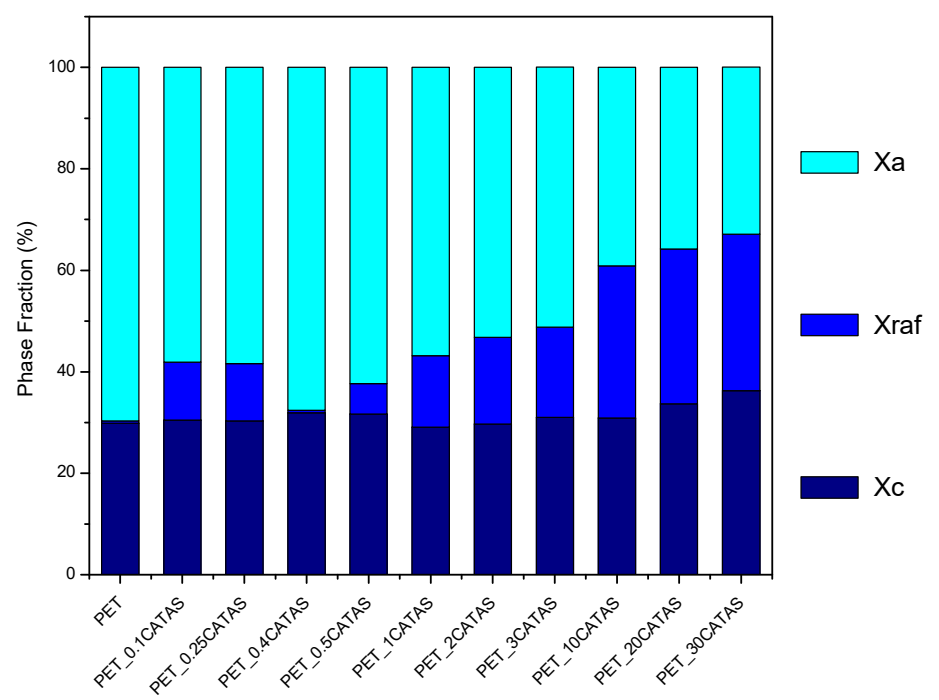

Figure 9. Evolution of different phase fractions for rPET and rPET_CATAS content.

As already observed, flexural test at a speed rate of $2 \mathrm{~mm} / \mathrm{min}$ shows a large strain for rPET and rPET_0.4CATAS that indeed have a very similar phases ratio with the addition of a possible interfacial slipping effect of the filler in the composite. Tensile test carried out at higher speed ( $5 \mathrm{~mm} / \mathrm{min})$ shows 
an increase in strength at low amount of CATAS, but it is necessary a larger percentage of filler to obtain the slipping effect at this strain rate. The blocking effect of $X_{\text {raf }}$ show its effect even on moduli that increased progressively with the CATAS as soon as the composite become fragile at higher amounts of filler.

\section{Conclusions}

Preparation, by melt extrusion, of CATAS reinforced rPET matrix for nanocomposites loaded at different levels was reported. Results from thermomechanical characterization indicated that CATAS content can be tailored, opening the use of these materials in unexplored industrially relevant applications that require high strength and thermal stability at high temperatures.

In detail, it was observed that when the CATAS content increased from 0.1 to $0.4 \mathrm{wt}$. $\%$, an increase for tensile strength and elastic moduli was observed. Nevertheless, a threshold weight amount $(0.4 \mathrm{wt}$. \%) of CATAS was also found, by formation at low loading, of a rigid amorphous fraction at the rPET/CATAS interface, that restricted the mobility, as shown by $\mathrm{G}^{\prime}$ values measured at temperature below and above $\mathrm{Tg}$ temperature. When the threshold was surpassed, a restriction of rPET/CATAS molecular chains mobility was also detected, due to the formation, of mechanical percolation networks in addition to physical restrictions (hydrogen and $\pi-\pi$ bonding). Additionally, enhanced thermal stability of CATAS filled rPET was registered at a high content due to chemical compatibility between synthetized Ca-Metal Organic Framework and the rPET matrix, rich in stable aromatic rings.

Given the chemical affinity of Ca-based salts and the rPET matrix and the simplicity of the processing methodology necessary to make these systems, this work can pave the way for the facile preparation of similar mixed-matrix materials.

Author Contributions: Conceptualization, F.D.; Data curation, F.L.; Investigation, F.D., F.S., F.L. and D.P.; Supervision, L.T.; Writing-original draft, F.D., F.S. and D.P.; Writing-review \& editing, D.P. All authors have read and agreed to the published version of the manuscript.

Funding: This research received no external funding.

Conflicts of Interest: The authors declare no conflict of interest.

\section{References}

1. Allen, R.D. Waste PET: A Renewable Resource. Joule 2019, 3, 910. [CrossRef]

2. Thomas, S.; Rane, A.V.; Kanny, K.; Abitha, V.K.; Thomas, M.G. Recycling of Polyethylene Terephthalate Bottles; William Andrew: Norwich, NY, USA, 2018.

3. Palkopoulou, S.; Joly, C.; Feigenbaum, A.; Papaspyrides, C.D.; Dole, P. Critical review on challenge tests to demonstrate decontamination of polyolefins intended for food contact applications. Trends Food Sci. Technol. 2016, 49, 110-120. [CrossRef]

4. Chowreddy, R.R.; Nord-Varhaug, K.; Rapp, F. Recycled Poly(ethylene Terephthalate)/Clay Nanocomposites: Rheology, Thermal and Mechanical Properties. J. Polym. Environ. 2019, 27, 37-49. [CrossRef]

5. Pegoretti, A.; Kolarik, J.; Peroni, C.; Migliaresi, C. Recycled poly(ethylene terephthalate)/layered silicate nanocomposites: Morphology and tensile mechanical properties. Polymer 2004, 45, 2751-2759. [CrossRef]

6. Tsai, T.-Y.; Bunekar, N.; Wu, T.-C. The Role of Organomodified Different LDHs on Recycled Poly(ethylene terephthalate) Nanocomposites. J. Chin. Chem. Soc. 2017, 64, 851-859. [CrossRef]

7. Kráčalík, M.; Mikešová, J.; Puffr, R.; Baldrian, J.; Thomann, R.; Friedrich, C. Effect of 3D structures on recycled PET/organoclay nanocomposites. Polym. Bull. 2007, 58, 313-319. [CrossRef]

8. Zare, Y. Recent progress on preparation and properties of nanocomposites from recycled polymers: A review. Waste Manag. 2013, 33, 598-604. [CrossRef]

9. Aoyama, S.; Ismail, I.; Park, Y.T.; Macosko, C.W.; Ougizawa, T. Higher-Order Structure in Amorphous Poly(ethylene terephthalate)/Graphene Nanocomposites and Its Correlation with Bulk Mechanical Properties. ACS Omega 2019, 4, 1228-1237. [CrossRef] 
10. Dyosiba, X.; Ren, J.; Musyoka, N.M.; Langmi, H.W.; Mathe, M.; Onyango, M.S. Preparation of value-added metal-organic frameworks (MOFs) using waste PET bottles as source of acid linker. Sustain. Mater. Technol. 2016, 10, 10-13. [CrossRef]

11. Doan, V.D.; Do, T.L.; Ho, T.M.T.; Le, V.T.; Nguyen, H.T. Utilization of waste plastic pet bottles to prepare copper-1, 4-benzenedicarboxylate metal-organic framework for methylene blue removal. Sep. Sci. Technol. 2020, 55, 444-455. [CrossRef]

12. Jones, P.G.; Ossowski, J.; Kus, P.; Dix, I. Three Crystal Structures of Terephthalic Acid Salts of Simple Amines. Z. Für Nat. B 2009, 64, 865-870. [CrossRef]

13. Kaduk, J.A. Terephthalate salts: Salts of monopositive cations. Acta Crystallogr. Sect. B Struct. Sci. 2000, 56, 474-485. [CrossRef] [PubMed]

14. Panasyuk, G.P.; Azarova, L.A.; Budova, G.P.; Izotov, A.D. Synthesis and characterization of ammonium terephthalates. Inorg. Mater. 2002, 38, 385-389. [CrossRef]

15. Panasyuk, G.P.; Khaddaj, M.; Privalov, V.I.; Miroshnichenko, I.V. Poly(ethylene terephthalate) Transformations during Autoclaving in Water Vapor. Plast. Massy 2002, 2, 27-31.

16. Hou, J.; Ashling, C.W.; Collins, S.M.; Krajnc, A.; Zhou, C.; Longley, L.; Johnstone, D.; Chater, P.A.; Li, S.; Coudert, F. Metal-organic framework crystal-glass composites. Nat. Commun. 2019, 10, 1-10. [CrossRef]

17. Mou, C.; Wang, L.; Deng, Q.; Huang, Z.; Li, J. Calcium terephthalate/graphite composites as anode materials for lithium-ion batteries. Ionics 2015, 21, 1893-1899. [CrossRef]

18. Sachdeva, S.; Koper, S.J.H.; Sabetghadam, A.; Soccol, D.; Gravesteijn, D.J.; Kapteijn, F.; Sudhölter, E.J.R.; Gascon, J.; De Smet, L.C.P.M. Gas phase sensing of alcohols by Metal Organic Framework-polymer composite materials. ACS Appl. Mater. Interfaces 2017, 9, 24926-24935. [CrossRef]

19. Stock, N.; Biswas, S. Synthesis of metal-organic frameworks (MOFs): Routes to various MOF topologies, morphologies, and composites. Chem. Rev. 2011, 112, 933-969. [CrossRef]

20. Schmidt, B.V. Metal-Organic Frameworks in Polymer Science: Polymerization Catalysis, Polymerization Environment, and Hybrid Materials. Macromol. Rapid Commun. 2019, 41. [CrossRef]

21. Wunderlich, B. Thermal Analysis of Polymeric Materials; Springer Science \& Business Media: Berlin/Heidelberg, Germany, 2005.

22. Matsuzaki, T.; Iitaka, Y. The crystal structure of calcium terephthalate trihydrate. Acta Crystallogr. Sect. B Struct. Crystallogr. Cryst. Chem. 1972, 28, 1977-1981. [CrossRef]

23. Alavi, M.A.; Morsali, A. Alkaline-earth metal carbonate, hydroxide and oxide nano-crystals synthesis methods, size and morphologies consideration. Nanocrystal 2011, 237-262. [CrossRef]

24. Mazaj, M.; Mali, G.; Rangus, M.; Žunkovič, E.; Kaučič, V.; Zabukovec Logar, N. Spectroscopic studies of structural dynamics induced by heating and hydration: A case of calcium-terephthalate metal-organic framework. J. Phys. Chem. C 2013, 117, 7552-7564. [CrossRef]

25. Dominici, F.; Puglia, D.; Luzi, F.; Sarasini, F.; Rallini, M.; Torre, L. A Novel Class of Cost Effective and High Performance Nanocomposites Based on Terephthalate Salts Reinforced Polyether Ether Ketone. Polymers 2019, 11, 2097. [CrossRef]

26. Liang, P.-C.; Liu, H.-K.; Yeh, C.-T.; Lin, C.-H.; Zima, V.T.Z. Supramolecular Assembly of Calcium MetalOrganic Frameworks with Structural Transformations. Cryst. Growth Des. 2011, 11, 699-708. [CrossRef]

27. Wang, L.; Mou, C.; Sun, Y.; Liu, W.; Deng, Q.; Li, J. Structure-property of metal organic frameworks calcium terephthalates anodes for lithium-ion batteries. Electrochim. Acta 2015, 173, 235-241. [CrossRef]

28. Mazaj, M.; Zabukovec Logar, N.A. Phase Formation Study of Ca-Terephthalate MOF-Type Materials. Cryst. Growth Des. 2015, 15, 617-624. [CrossRef]

29. Howarth, A.J.; Liu, Y.; Li, P.; Li, Z.; Wang, T.C.; Hupp, J.T.; Farha, O.K. Chemical, thermal and mechanical stabilities of metal-organic frameworks. Nat. Rev. Mater. 2016, 1, 15018. [CrossRef]

30. Ahani, M.; Khatibzadeh, M.; Mohseni, M. Preparation and characterization of Poly(ethylene terephthalate)/hyperbranched polymer nanocomposites by melt blending. Nanocomposites 2016, 2, $29-36$. [CrossRef]

31. Golpour, M.; Pakizeh, M. Preparation and characterization of new PA-MOF/PPSU-GO membrane for the separation of KHI from water. Chem. Eng. J. 2018, 345, 221-232. [CrossRef]

32. Strain, I.N.; Wu, Q.; Pourrahimi, A.M.; Hedenqvist, M.S.; Olsson, R.T.; Andersson, R.L. Electrospinning of recycled PET to generate tough mesomorphic fibre membranes for smoke filtration. J. Mater. Chem. A 2015, 3, 1632-1640. [CrossRef] 
33. Kim, J.; Choi, J.; Soo Kang, Y.; Won, J. Matrix effect of mixed-matrix membrane containing CO2-selective MOFs. J. Appl. Polym. Sci. 2016, 133. [CrossRef]

34. Shabafrooz, V.; Bandla, S.; Allahkarami, M.; Hanan, J.C. Graphene/polyethylene terephthalate nanocomposites with enhanced mechanical and thermal properties. J. Polym. Res. 2018, 25, 256. [CrossRef]

35. Wang, X.-S.; Li, X.-G.; Yan, D. Thermal decomposition kinetics of poly (trimethylene terephthalate). Polym. Degrad. Stab. 2000, 69, 361-372. [CrossRef]

36. Cacho-Bailo, F.; Téllez, C.; Coronas, J. Interactive thermal effects on metal-organic framework Polymer composite membranes. Chem. A Eur. J. 2016, 22, 9533-9536. [CrossRef] [PubMed]

37. Chung, S.-C.; Hahm, W.-G.; Im, S.-S.; Oh, S.-G. Poly(ethylene terephthalate)(PET) nanocomposites filled with fumed silicas by melt compounding. Macromol. Res. 2002, 10, 221-229. [CrossRef]

38. Qiu, G.; Tang, Z.L.; Huang, N.X.; Gerking, L. Dual melting endotherms in the thermal analysis of Poly(ethylene terephthalate). J. Appl. Polym. Sci. 1998, 69, 729-742. [CrossRef]

(C) 2020 by the authors. Licensee MDPI, Basel, Switzerland. This article is an open access article distributed under the terms and conditions of the Creative Commons Attribution (CC BY) license (http://creativecommons.org/licenses/by/4.0/). 